\title{
Televizyon Programları, Sembolik Tüketim Ve Toplumsal Yansımaları
}

\author{
Tamer BARAN $^{1} \quad$ Serhat BARAN ${ }^{2}$ \\ ${ }^{1}$ Pamukkale Üniversitesi, Kale MYO, Kale, Denizli \\ ${ }^{2}$ Yüksek Lisans Öğrencisi, Pamukkale Üniversitesi, SBE, Denizli
}

\begin{abstract}
Özet
Televizyon (TV) teknolojik gelişimin insanlara sunduğu en önemli araçlardan birisidir. İnsanlar için özellikle boş vakitlerini değerlendirdikleri bir eğlence aracıdır. Bununla birlikte insanlar izledikleri TV programlarındaki kişileri kendilerine model olarak almakta, bu kişiler gibi hareket etmekte ve bu kişiler gibi yaşamak istemektedirler. Bu durum pazarlamada sembolik tüketim olarak ifade edilen tüketim biçimini ortaya çıkarmaktadır. Sembolik tüketim, ürün, hizmet ya da markaların sembolik değerlere göre değerlendirilip tüketilmesidir. Tüketiciler kullandıkları ürün ve markalar aracılığıyla karşısındaki kişilere, kimliklerine ve sosyal statülerine ilişkin mesajlar gönderirler. Sembolik tüketimin ekonomik, psikolojik, sosyal vb. bir takım sonuçlarının olması kaçınılmazdır. Bu çalışmanın amacı TV'nin tüketicilerin tüketim davranışındaki rolünü ve neden olduğu sorunları ortaya koymaktır. Bu amacı gerçekleştirmek için ilk bölümde Türkiye'de TV izleme alışkanlıklarına ilişkin veriler sunulmuş, ikinci bölümde sembolik tüketim kavramı ve TV'nin sembolik tüketim üzerindeki rolü, üçüncü bölümde sembolik tüketimin toplumsal sonuçları açıklanmıştır. Son bölümde ise TV'den kaynaklı toplumsal sorunların çözümüne ilișkin paydaşların sorumlulukları belirtilerek bu sorunların çözümüne ilișkin öneriler sunulmuștur.

Anahtar Kelimeler: Televizyon Programları, Sembolik Tüketim, Sorun, Toplumsal Sorun
\end{abstract}

\section{Television Programmes, Symbolic Consumption and Societal Reflections}

\begin{abstract}
Television (TV) is one of the most important tools of technological development to offer people. However audience take as a model, they are acting like and want to live like to person who are on TV programs. This situation is indicated as symbolic consumption in marketing literature. In symbolic consumption products, services and brands are consumed according to symbolic values. Consumers send messages to another person related their identity and social status through the use of products and brands. It is unavoidable to be economic, psychological, social etc. results of symbolic consumption. The purpose of this study reveals the role of TV on consumption behaviour of consumer and caused problems by TV. To achieve this purpose in the first section development of TV is mentioned and present data related to TV watching habits of Turkish audience, in the second section symbolic consumption concept is explained and the role of TV on symbolic consumption is included, in the third section social consequences of symbolic consumption is explained. In the last section responsibilities of stakeholders are indicated for solution of the social problems caused by TV and propositions are represented related to solution of these problems.
\end{abstract}

Key Words: TV Programs, Symbolic Consumption, Problem, Social Problem.

\section{Giriş}

Son yıllarda baş döndürücü bir hızla gelişim gösteren teknoloji hayatın her alanında olduğu gibi pazarlama alanında da etkisini göstermektedir. Teknolojinin insanlığa sunduğu en önemli araçlardan biri olan televizyon (TV) son yıllarda insanların belki de en fazla vakit ayırdıkları eğlence aracı haline gelmiştir. İnsanlar günlük faaliyetlerinin yorgunluğunu atmak için boş zamanlarının önemli bir kısmını yarışma, dizi, magazin vb. TV programlarını izleyerek geçirmektedirler. Bu noktada TV izleyicileri reklam vb. programlarla bilinçli ya da yarışma, dizi, magazin vb. programlarla bilinçaltını etki ederek tüketime sevk edilmektedirler. İzleyiciler reklam, yarışma, dizi, magazin vb. programlarda karşılaştıkları ünlüler gibi yaşamaya, onlar gibi giyinmeye, onların kullandıklarını kullanmaya özendirilmektedirler. Bu durum pazarlamada sembolik tüketim olarak ifade edilmektedir. Sembolik tüketimle tüketiciler kullandıkları ürün ve markalar aracılığıyla karşısındakilere statü, sosyal sınıfa ilişkin mesajlar verirler. Bununla birlikte, herhangi bir nedenle bu ürün ya da markaları kullanamayan tüketiciler ise bu ürün ve markaları kullanabilmek için bir takım bedeller ödemeye kendilerini hazır görmektedir. Bu noktada toplumsal bir takım sorunların ortaya çıkması durumu söz konusu olmaktadır. Bu çalışmanın amacı TV'nin tüketicilerin tüketim davranışındaki rolünü ve neden olduğu sorunları ve bu sorunların çözümüne katkı sağlamaya yönelik önerileri ortaya koymaktır. Bu amacı gerçekleştirmek için ilk bölümde Türkiye'de TV izleme alışkanlıklarına ilişkin veriler sunulmuş, ikinci bölümde sembolik tüketim kavramı ve TV'nin sembolik tüketim üzerindeki rolü, üçüncü bölümde sembolik tüketimin toplumsal sonuçları açıklanmıştır. Son bölümde ise TV'den kaynaklı toplumsal sorunların çözümüne ilişkin paydaşların sorumlulukları belirtilerek bu sorunların çözümüne ilişkin öneriler sunulmuştur.

\section{Televizyonun Gelişimi Ve Türkiye'de Televizyon Programları}

İlkel çağlardan günümüze insanların çeşitli ihtiyaçlarını gidermede önemli bir rol oynayan iletişim, elektriğin ve frekans dalgalarının kullanılmasıyla birlikte teknolojik bir boyuta taşınmıştır. Kitle iletişimi açısından değerlendirildiğinde insanoğlunun en sık kullandığı iletişim aracının TV olduğu ifade edilebilir. TV sağladığı iletişimle mesafeyi kısaltmış bu yolla da insanların çok uzak yerlerde gerçekleşen olaylardan çok kısa bir süre içerisinde haberdar olmasına imkân sağlamıştır. Dünya'da TV'yle ilgili olarak ilk teknik buluş İrlandalı bir telgrafçı olan Andrew May tarafından 1873 yılında yapılmış, ilk düzenli TV yayını 1936 yılında İngiltere'de başlamıştır (Aziz, 1981: 12-14). 
Türkiye'de ilk TV yayını 1952 yılında İstanbul Teknik Üniversitesi tarafından gerçekleştirilmiş (Özgen, 2003:424), 31 Ocak 1968 tarihinden itibaren düzenli olarak Türkiye Radyo ve Televizyon Kurumu (TRT) tarafindan yapılmaya başlanmıştır (wikipedia, 2013). 1990'lı yıllar Türkiye'de TV yayıncılığında özel sektörün gelişmeye başladığı yıllardır. İlk olarak Star-1 TV yayın hayatına başlamış, bunu diğer TV kanalları takip etmiş ve günümüzde bu sayı karasal yayın yapan 247, uydu üzerinden yayın yapan 205 ve kablo üzerinden yayın yapan 101 TV olmak üzere 553'e ulaşmıştır. (http://www.ahaber.com.tr, 2012).

TV kanallarının sayısındaki bu artış bu sektöre olan ilgiye artışı da beraberinde getirmekte ve bu sektördeki genel durumu ortaya koymaya yönelik raporlar düzenlenmektedir. Bu raporlardan bir tanesi de 2012 yılına ilişkin RTÜK (2013) tarafından yayınlanan rapordur. Tablo 1'de bahsedilen raporda geçen TV programlarının izlenme sıklığı verilmiştir. Tabloya bakıldığında 2012 yılı için en fazla izlenen program türünün \%76,7 ile yerli diziler olduğu görülmektedir. Dizileri sırasıyla haberler, Türk filmleri, yarışma programları takip etmektedir. Tabloda en az izlenen program türünün ise kadın kuşak programları olduğu görülmektedir.

Tablo 1: TV Programlarının İzlenme Sıklığı Sıralaması

\begin{tabular}{|l|c|c|c|}
\hline & İzliyorum & $\begin{array}{c}\text { Ara sıra } \\
\text { izliyorum }\end{array}$ & İzlemiyorum \\
\hline 1- Yerli Diziler & 76,7 & 13,1 & 10,2 \\
\hline 2- Haberler & 74,5 & 15,4 & 10,1 \\
\hline 3- Türk Filmleri & 49,7 & 24,3 & 25,9 \\
\hline $\begin{array}{l}\text { 4- Yarışma } \\
\text { Programları }\end{array}$ & 42,4 & 23,0 & 34,7 \\
\hline 5- Yabancı Filmler & 39,4 & 22,2 & 38,4 \\
\hline 6- Belgeseller & 38,2 & 21,3 & 40,5 \\
\hline 7- Spor Programları & 36,0 & 13,3 & 50,7 \\
\hline $\begin{array}{l}\text { 8- Müzik / Eğlence / } \\
\text { Klip }\end{array}$ & 34,4 & 19,1 & 46,5 \\
\hline 9- Dini Programlar & 31,2 & 20,2 & 48,6 \\
\hline $\begin{array}{l}\text { 10- Açı Oturum ve } \\
\text { Tartışma } \\
\text { Programları }\end{array}$ & 30,8 & 20,1 & 49,0 \\
\hline $\begin{array}{l}\text { 11- Güldürü / Talk } \\
\text { Show }\end{array}$ & 26,5 & 20,7 & 52,8 \\
\hline 12- Yabancı Diziler & 23,0 & 16,1 & 60,9 \\
\hline $\begin{array}{l}\text { 13- Magazin } \\
\text { Programları }\end{array}$ & 20,6 & 18,1 & 61,3 \\
\hline $\begin{array}{l}\text { 14- Gerçek Hayat } \\
\text { Hikayeleri }\end{array}$ & 16,6 & 13,4 & 69,9 \\
\hline $\begin{array}{l}\text { 15- Kadın Kuşak } \\
\text { Programları }\end{array}$ & 15,8 & 10,4 & 73,7 \\
\hline $\begin{array}{l}\text { Kaynak: RTUK } \\
\text { Magar| }\end{array}$ & & & \\
\hline
\end{tabular}

Kaynak: RTÜK 2012 Faaliyet Raporu, S. 64

Yayınlanan raporda hafta içi ve hafta sonu TV izleme saatleri Grafik 1 ve Grafik 2'de verilmiştir. Grafik 1'de de görüldüğü gibi hafta içi günlerde TV'nin en çok izlendiği saat aralıkları \% 61 ile 21.01-00.00 saatleri arasıdır. Bu saat aralıklarında TV kanallarında dizilerin ağırlıklı bir şekilde yer aldığını düşünürsek Tablo 1'de verildiği üzere dizilerin izlenme oranının en yüksek değere sahip olmasını doğal karşılayabiliriz. Hafta içi TV'nin en çok izlendiği ikinci saat dilimi yaklaşık \% 54'lük oranla 18.01-21.00 saatleri arasıdır. Hafta içi en az TV izlenen saatler ise \% 1'lik oranla 03.0006.01 aralığıdır.

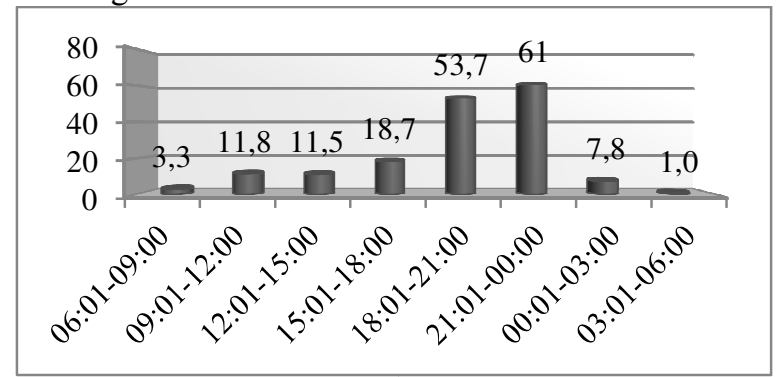

Grafik 1: Hafta İçi TV İzleme Saatleri

Kaynak: RTÜK 2012 Faaliyet Raporu, S. 63

Hafta sonu TV izleme saatlerine bakıldığında hafta içinde olduğu gibi en fazla TV izlenen saatler yaklaşık \%70 ile 21.01-00.00 aralığıdır. Bu zaman aralığını yaklaşık \%57 ile 18.01-21.00 aralığ izlemektedir. Hafta sonu TV'nin en az izlendiği zaman aralığı ise yaklaşık \% 2 ile $03.01-06.00$ arasıdır.

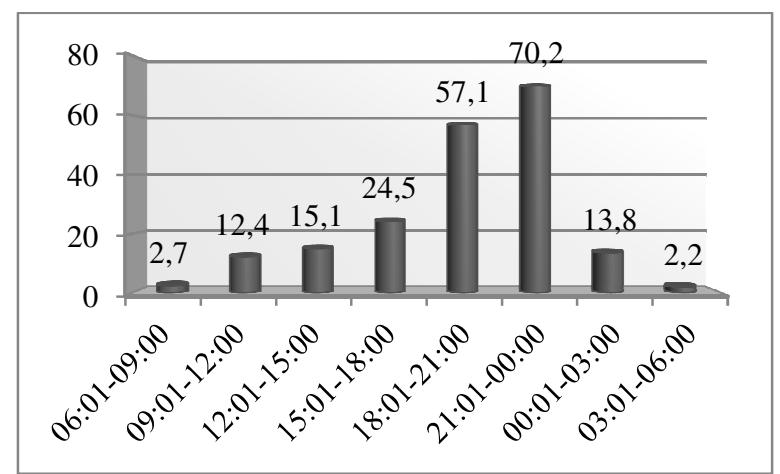

Grafik 2: Hafta Sonu TV İzleme Saatleri

Kaynak: RTÜK 2012 Faaliyet Raporu, S. 64

\section{Sembolik Tüketim}

Sanayinin gelişimini tamamlamadığı ve kapitalist ekonomik sistemin toplumsal yaşamdaki etkisinin bu derece etkili olmadığı dönemlerde, bireyler sosyal ilişkilerini doğal düzen içinde sürdürmüşlerdir. Bu dönemlerdeki ekonomik faaliyetlerde insanlar ihtiyaçları kadar üretmiş, ürünlerini bir bedel karşılığı sunmamış ve kâr endişesi taşımamışlardır. Ancak 20. yüzyılda sanayinin gelişimiyle birlikte toplumsal yaşamda önemli değişiklikler meydana gelmiş, çalışma, üretim, sermaye ve mümkün olan en fazla kârı elde etmeye çalışma en önemli amaç haline gelmiştir. Bilimsel bilgi ve akıl almaz teknolojik gelişim insan emeğine duyulan ihtiyacı azaltmış, dolayısıyla tüketim yükselen değer olarak üretimin yerini almıştır. Artık arzu edilen durum üretimin değil tüketimin maksimize edilmesidir. Çünkü gelişen teknoloji hayal edilemeyecek miktarda ve hızda üretimin gerçekleşmesine imkân sağlamaktadır. $\mathrm{Bu}$ durumda 
çözülmesi gereken problem gerçekleştirilen üretimin eritilmesi bir başka ifadeyle tüketilmesidir (Şentürk, 2008).

Sanayi devriminin bir sonucu olarak ortaya çıkan ekonomik modernitenin (wikipedia, 2013) ilerleyen sürecinde üretimde meydana gelen artış beraberinde ortaya çıkan ürünlerin tüketilmesi gibi bir problemi de beraberinde getirmiştir. $\mathrm{Bu}$ noktada özellikle pazarlama alanındaki akademisyenler ve uygulamacılar bu problemi aşmak için yollar aramışlardır. Bu noktada ortaya çıkan çözüm yollarından biri de sembolik tüketimdir (Özdemir, 2007: 5).

Sembol bir nesne ya da fikri ifade eden simge olarak tanımlanmaktadır (TDK, 2013). İnsanoğlunun diğer türlerde bulunmayan özelliklerinden bazıları, zoolojik kökenli olmayan amaçları, arzulu fantezileri, değer bilinci, uygulanması mümkün olmayan heyecanları ve yaşam sonrası bilincidir. Yalnızca insanda görülen bu özelliklerin bir sonucu olarak insanoğlunda sembolleştirme gereksinimi ortaya çıkmış ve bu gereksinim insanoğlu için öncelikli gereksinimlerden biri haline gelmiştir (Bocock, 1997: 77).

Tüketiciler ihtiyaçlarını karşılarken fizyolojik, psikolojik, sosyal vb. etkileşimi de göz önünde bulundurarak tüketimde bulunurlar. $\mathrm{Bu}$ açıdan değerlendirildiğinde tüketimi yalnızca ürünlerin satın alınması, kullanılması ve atılması olarak değerlendirmemenin gerekliliği ortaya çıkar. Tüketiciler, satın aldıkları ürünlerden haz alma, fayda sağlamayı da amaçlar. $\mathrm{Bu}$ noktada tüketicilerin satın alma sonrası sağladıkları faydalardan biri de satın aldıkları ürünler aracılığıyla kimliklerini, sınıflarını, statülerini ifade ediyor olmalarıdır (Torlak, 2010). Pazarlamada bu durum sembolik tüketim olarak ifade edilmektedir. Sembolik tüketim, ürün ya da markaların sembolik değerlerine göre değerlendirilerek tüketilmesi durumunu ifade eder (Koç, 2011: 265). Tüketiciler, satın aldıkları ürün ya da markalar aracılığıyla bulundukları sosyal sınıfı, statüyü, kimliklerini vb. özellikleri karşılarındaki kişilere ifade etme yoluna gidebilirler (Odabaş1, 2003: 57).

Bocock'a (1997: 74) göre, her geçen gün daha fazla tüketici kendi kimliğini oluşturma çabası içerisindedir ve bu çabanın gerçekleştirilmesindeki en önemli araçlardan biri tüketimdir. Tüketiciler örneğin giyim eşyasını, takıyı, mobilyayı vb. kim olduklarıyla ilgili zaten var olan duygularını dışa vurmak için satın almazlar. Tüketiciler aksine kimliklerini oluşturmada satın aldıkları şeyleri birer araç olarak kullanırlar. Örneğin, günümüz dünyasında bir tüketici kendiliğinden "cazip bir kadın" ya da "yakışıklı bir erkek" olamaz. Tüketiciler kimliklerini oluşturmaya yardımcı olacağını düşündükleri ürünleri ya da markaları tüketerek arzuladıkları kişi olmaya ve kendileriyle ilgili bu imajı ve kimliği sürdürmeye gayret ederler. Giysiler, parfümler, otomobiller, yiyecekler vb. ürün ya da markalar bu süreçte tüketicilere yardımcı olacak araçlardır ve bu araçlar tüketicinin x ya da y olduğunu gösterir.

Baudrillard'a (1997: 89) göre, günümüz tüketicileri yeme, içme vb. birincil gereksinimlerinden çok duygusal gereksinimlerini doyurmaya çalışmaktadırlar. Bocock (1997: 101) Williamson'un pek çok tüketicinin yaşamlarında seçtikleri anlamın ürettiklerinden çok tükettikleriyle oluştuğunu ifade ettiğini belirtmiştir.

4. Sembolik Tüketimde Televizyon Programlarının Rolü Ve Sembolik Tüketimin Toplumsal Yansımaları
Gelişen teknolojinin insanoğluna sunduğu belki de en önemli araç TV'dir. Başta kitlesel bir iletişim aracı olarak kullanılan TV zaman içerisinde bu işlevinin yanı sıra bir eğlence ve boş zamanların değerlendirilmesi gibi işlevler de kazanmıştır. TV zamanla etkinliğini daha da artırmış ve TV'siz bir yaşam insanlar tarafından neredeyse imkânsız gibi düşünülmeye başlanmıştır. İzleyiciler zaman zaman TV'nin olumsuz sonuçlarından şikâyet etseler de kendilerini TV'nin büyüsüne kaptırmaktan alıkoyamamaktadırlar. Zaman içerisinde artan etkinliğiyle birlikte TV kişisel değerlerimizden düşünme ve hissetme biçimimize, aile ilişkilerimizden sosyal ilişkilerimize kadar hayatımızın birçok alanını etkilemenin ötesinde biçimlendiren bir araç haline gelmiştir (Peker, 1997: 19). Bunun yanı sıra Torlak (2010) ve Karaboğa (2007) TV'nin tüketim üzerinde etkili olduğunu belirtmişler, Karaboğa (2007) TV programlarının izleyiciye gücün ve hâkimiyetin tüketimle elde edileceğini ve izleyicinin ne kadar fazla tüketirse o kadar güçlü olacağı mesajını verdiğini ifade etmiştir. Bu noktada öne çıkan TV programları olarak diziler, yarışma programları, magazin programları ve TV reklamları başı çekmektedir (Ceylan, 2012, Barokas, 2011, Karacoşkun, 2002).

Son yıllarda TV'lerde sayıları önemli ölçüde artan ve toplumsal değerlerden uzak dizilere, magazin programlarına ve yarışmalara rastlanmaktadır. Dizilerde ülkede yaşayanların ortalama yaşam standardının çok üzerinde bir yaşam izleyicilere sunulmakta ve senaryodan ibaret olan bu yaşam standardının toplumun genelinde var olduğu gibi bir hava oluşturulmaktadır. Magazin programlarında toplumun genel ahlak kurallarının dışında, insan onuruna yakışmayan görüntüler izleyicilere sunulmakta, toplumsal değerler ayaklar altına alınmaktadır. Benzer durum yarışma programları için de geçerlidir. $\mathrm{Bu}$ programlara katılan insanlar istediklerini elde etmek için birbirlerini ezmekten çekinmemekte ve magazin programlarında olduğu gibi bu programlarda da toplumsal değerler ayaklar altına alınmaktadır (Ceylan, 2012, Kallek, 2010).

Bunların yanı sıra yayınlanan TV reklamları izleyicileri yalnızca sahip olduklarıyla var olacakları aksi takdirde bir hiç olacakları düşüncesini besleyerek ve destekleyerek izleyiciler için yapay gereksinimler üretmekte ve insanları doyumsuzluğa sevk etmektedir. TV reklamı veren firmalar daha fazla ürün satmak ve kârlılıklarını artırmak için reklamlarında sanatçılara, mankenlere, sporculara yer vererek bu kişileri tüketiciye birer model olarak sunmakta ve kendi ürünlerini kullanmaları durumunda bu ünlülerin sahip oldukları prestije sahip olacakları mesajı vermektedirler (Şentürk, 2008, Okumuş, 2009).

Yukarıda bahsedilen TV programlarının psikolojik, toplumsal, ekonomik, sonuçlarının olması kaçınılmazdır. Diziler, magazin programları vb. TV programlarında izleyicilere model olarak sunulan kişiler gibi yaşayabilmek, onların giydiğini giyebilmek, onların kullandığı ürünleri ya da markaları kullanabilmek için tüketicilerin belirli bir gelir düzeyine sahip olmaları gerekir. Özellikle bu gelir düzeyine sahip olmayan ailelerin çocuklarının bu modelleri taklit etmek için suç işlemeleri imkân dâhilindedir. Bu çocukların amaçlarına ulaşmak için, hırsızlık, gasp vb. suçları işlemesi söz konusu olabilecektir. Diğer yandan gelir düzeyi yeterli olsa bile çocuklarının her istediğini almayı doğru bulmayarak çocuklarının taleplerini geri çevirebilmekte, bu durum ise çocukta yoksunluk ya da kırgınlık duygusu oluşturabilmektedir. Yukarıda bahsedilen TV programlarının 
olumsuz etkilerinden bir başkası ekonomik etkidir. Özellikle reklamlarda izleyiciye sunulan modeller aracilığıyla izleyicilere yapay gereksinimler oluşturularak izleyiciler israfa yönlendirilmekte, bu durum ise aile içinde şiddete varan sorunlara neden olmaktadır.

\section{Sonuç ve Öneriler}

Teknolojinin insanlığa sunduğu en önemli araçlardan biri olan TV zaman içerisinde iletişim işlevinin dışında eğlence ve boş zamanların değerlendirildiği bir araç haline gelmiştir. TV'nin zaman içerisinde artan bu etkinliği pazarlama akademisyenlerinin ve uygulamacılarının da dikkatini çekmiş ve TV pazarlamacılar için çok önemli bir mecra haline gelmiştir. Pazarlamacılar gerek reklam kuşaklarıyla gerekse diziler, magazin programları, yarışmalar vb. programlar aracılığıyla tüketicilere ulaşmaya çalışmaktadırlar. Bu noktada pazarlamacılar TV programlarında futbolcular, mankenler, sanatçılar gibi ünlüleri kullanarak tüketicilere kendi ürünlerini kullanmaları halinde ünlülerin sahip olduğu prestije sahip olabilecekleri mesajını vermektedirler. TV programlarında geçen ürün ya da markaların satın alınamaması psikolojik, ekonomik, toplumsal bir takım sonuçları beraberinde getirmektedir.

$\mathrm{Bu}$ çalışmanın neticesi olarak bu olumsuzluklar için pazarlamacılara, TV yapımcıları, yöneticileri ve kanal yöneticileri ile izleyicilere çözüm önerileri sunulmuştur. Özellikle pazarlamacılara ve TV yapımcıları ve yöneticilere sunulan öneriler ahlak temellidir. Bu noktada pazarlamacılar "her yolu mubah sayarak" ve "her şeye rağmen" kâr elde etmeyi hedefleyerek tüketicileri doyumsuzluğa ve hep daha fazla tüketmeye sevk etmek yerine daha toplumsal düşünmeli, bu gemide hep birlikte var olduğumuzu unutmadan hareket etmelidir. Bu şekilde tüketicilerin israfa kaçmasının bir nebze de olsa önüne geçilebilecek, firmalar kısa vadede kârlarından feragat etmiş gibi görünse de uzun vadede hem kendileri hem de toplumun geneli bu durumdan kazançlı çıkacaktır.

Benzer şekilde TV yapımcıları, yöneticileri ve kanal yöneticileri "bize kazanç sağlayan her programı yayınlamalıyız" düşüncesinden sıyrılarak toplumun yararını gözeten programlar hazırlamalı, kendilerine gelen her reklamı kabul etmek yerine "denetçi aracılık" yoluyla izleyicileri tüketim çılgınlığına götürecek reklamları eleyebilmelidirler. Ayrıca TV yapımcıları, yöneticileri ve kanal yöneticileri toplumun çok azının sahip olduğu yaşam standardının toplumun geneline hâkimmiş gibi göstermekten vazgeçmeli ve toplumun genel ahlak kuralları ve kültürüne uygun programları izleyiciye sunmalıdır.

$\mathrm{Bu}$ çalışmada -dört bir yandan abluka altında olduğu düşünüldüğünden- en masum kesim olarak kabul edilen izleyiciler ise diziler, yarışma programları, reklamlar ve hatta magazin programlarının birçoğunun kurgudan ibaret olduğunu kabul etmeleri ve buna uygun hareket etmeleri gerekmektedir. Bununla birlikte izleyiciler özellikle çocukları TV'den mümkün olduğunca uzak tutmalı ve çocukları TV'nin etkisine girmemeleri için dikkat etmelidirler. Ayrıca TV programlarında karşılaştıkları olumsuzlukları ilgili kuruma şikayet olarak iletmeli ve tüketicinin kral olarak kabul edildiği günümüzde TV'leri toplumun ahlak ve kültürüne uygun programlar hazırlamaları konusunda yönlendirmelidirler.

Sonuç olarak, TV kaynaklı sorunların çözümü için paydaşların tamamına önemli görevler düşmektedir. Bu görevlerin yerine getirilmesi işletmeler açısından kısa vadede kazançlı bir durum gibi görünmeyebilir. Ancak insan ihtiyacının sınırsız, kaynakların ise sınırlı olduğu ve toplumdaki yozlaşmanın ve kültür erozyonunun paydaşların tamamını bir şekilde olumsuz etkileyeceği düşünüldüğünde uzun vadede bu görevlerin yerine getirilmesinin her kesime fayda sağlayacağı kesindir.

\section{Kaynakça}

Aziz, Aysel, (1981), Radyo Ve Televizyona Giriş, Ankara Üniversitesi Siyasal Bilgiler Fakültesi Yayınları, Ankara.

Barokas, S. Kırlar, (2011), Büyümüş De Küçülmüşler, Bir Reklam Çözümlemesi "Pınar Sosis", Arel Üniversitesi İletişim Fakültesi İletişim Çalışmaları Dergisi, Cilt: 1, Sayı: 1, S. 159-183.

Baudrıllard, Jean, (1997), Tüketim Toplumu, (Çev.: Hazal Deliçaylı, Ferda Keskin,, Ayrıntı Yayınları, İstanbul.

Bocock, Robert, (1997), Tüketim, (Çev.: İrem Kutluk), Dost Kitabevi, Ankara.

Ceylan, Yilmaz, (2012), Toplumsal Değerler Ve Medya Etiği, Dicle Üniversitesi Sosyal Bilimler Enstitüsü Dergisi, Y1l: 4, Say1: 7, S. 45-58

Http://Tdk.Gov.Tr, (13.09.2013).

Http://Tr.Wikipedia.Org/Wiki/Modernite, (11.09.2013).

Http://Tr.Wikipedia.Org/Wiki/T\%C3\%Bcrkiye'deki_Tele vizyon_Kanallar\%C4\%B1_Listesi, (E.T., 15.09.2013).

Http://Www.Ahaber.Com.Tr/Gundem/2012/04/14/Turkiy ede-Kac-Tv-Kanali-Var, (14.09.2013).

Kallek, Cengiz, (2010), İnsanın Metalaştırılmasına Metaı Kişileştiren Hz. Peygamber'den Reddiye, İstanbul Ticaret Odası Tüketim Ve Değerler, Altınoluk Yayın San. A.Ş., S. 107-138.

Karaboğa, Tahir, (2007), Bir Kitle İletişimsizlik Aracı Olarak Televizyon, Sosyoloji Notları Dergisi.

Karacoşkun, M. Doğan, (2002), Bireysel Ve Toplumsal Çözülmede Televizyon Faktörü Üzerine Düşünceler, Eskidergi.Cumhuriyet.Edu.Tr/Makale/341.Pdf.

Koç, Erdoğan, (2011), Tüketici Davranışı Ve Pazarlama Stratejileri, Global Ve Yerel Yaklaşım, Seçkin Yayıncılık, Ankara.

Odabaşı, Yavuz, Barış, Gülfidan, (2002), Tüketici Davranış1, Kapital Medya Hizmetleri A.Ş., İstanbul.

Okumuş, Ejder, (2009), Bedene Müdahalenin Sosyolojisi, Şarkiyat İlmi Araştırmalar Dergisi, Sayı: 2, S. 1-15.

Özdemir, Şefika, (2007), Hazcı Tüketim Davranışlarında Televizyonun Rolü: Sdü Öğrencileri Üzerine Bir Araştırma, Süleyman Demirel Üniversitesi Sosyal Bilimler Enstitüsü Yayınlanmamış Yüksek Lisans Tezi, Isparta.

Özgen, Murat, (2003), Türkiye'de Televizyon Yayıncılığının Gelişimi Ve Yasal Çerçevesi, İstanbul Üniversitesi İletişim Fakültesi Dergisi, Sayı 17, S. 423-433.

Rtük (2013), Televizyon İzleme Eğilimleri Araştırması2012, Ankara.

Şentürk, Ünal, (2008), Modern Kontrol: Tüketim, Cumhuriyet Üniversitesi Sosyal Bilimler Dergisi, Cilt: 32, No: 2, S. 221-239. 
Torlak, Ömer, (2010), Gündelik Hayatta Tüketime Yön Veren Değerlerdeki Değişim, İstanbul Ticaret Odası Tüketim Ve Değerler, Altınoluk Yayın San. A.Ş., S. 47-66. 